\title{
Investigation of the amount of attention to multicultural education approach in education department of north Khorasan
}

\begin{abstract}
This research is aimed at investigating the amount of attention to multicultural education approach in education department of North Khorasan. In terms of purpose, this research is an applied one and in terms of method, this is a descriptive-survey research. The research population includes all the second grade teachers of girls' elementary schools in Bojnord city who are 100 people. In this research, total count sampling method had been used. So, all the 100 people of the population were selected. For collecting data, two methods of library and field data collection have been used. Data collection tool was a researcher-made questionnaire. Validity of the variables was evaluated as $0 / 86$ by Cronbach's alpha coefficient. Content validity of the questionnaire was confirmed by the experts. In order to statistically analyze the data, factor analysis method using SPSS 19 software and structural model method using LISREL $8 / 8$ software were employed. The results should that regarding the output of LISREL software and the obtained value of path coefficient, the component of the teacher with the path coefficient of 0/69 from the structural dimension and the component of the goals with the factor loading of $0 / 43$ from the content dimension have the highest effect among the components recognized as being effective on multicultural education, and the other components are at the lower degrees.
\end{abstract}

Volume 3 Issue 2 - 2019

\author{
Shokat Alidadiyani, Mahbubeh \\ Spleymanpouromran, Roya Afrasiabi \\ Department of Educational Management, Islamic Azad \\ University, Iran
}

Correspondence: Shokat Alidadiyani, Ph.D. student, Department of Educational Management, Islamic Azad University, Bojnord branch, Iran, Email iranish634@gmail.com

Received: January 23, 2019 | Published: April 01, 2019

Keywords: education approach, multicultural education, approach, education, department, multicultural

\section{Introduction}

Teachers are the major correspondents of the education system. Competency of every education system is equal to the competency of the teachers of that system, and quality of education system depends on the quality of teachers of that society. In fact, no country can go beyond the level of its teachers. Accordingly, teacher training is worth the strongest careful and continuous attention. Executive guarantee of improvements of an education system is the presence of good and efficient teachers. Success or failure of the best or the weakest curriculums depends on the teacher's designing and executing. Looking at the changes of evolutions of education systems at national and international levels, it becomes evident that without considering a specific role for the teachers, none of the goals and desires will be achieved and education systems cannot achieve any scientific change or innovation. Before beginning the discussion on multicultural teaching and the relevant topics, understanding the concepts such as culture, identity, and ethnicity, multicultural society, globalization, and pluralism is necessary. Gidnez defines culture as life styles of group members of society. In his opinion, culture is the interaction of how to wear, customs, marriage, family life, working patterns, rituals, and recreation. Nito considers culture as including values, traditions, sociopolitical relationships, and worldviews which are created, shared, and transformed by a group of people who are connected to each other by shared history, geographical location, language, social class, religion, or other shared identities. As human societies have different cultures, every culture forms a special identity. Therefore, every society has a distinguished identity due to having a special culture. In terms of pluralism, identity is a characteristic which originates from a set of customs, behaviors, legacies, specific social group, and a set of specific experiences. ${ }^{1}$ Since one of the aspects of multicultural education is reviewing different cultural identities within a pluralistic society and making the learners familiar with the unique characteristics of these identities, consideration of this aspect in the process of training and educating the future teachers seems to be necessary. Therefore, multicultural society should allow its members to define their identities in the group or groups to which they feel a close affinity, and also every group is allowed to form its genuine demands and differences according to its situation. ${ }^{2}$

The issue of multiculturalism has a long history in the world. Although the framework of multiculturalism in the contemporary world is the same as its frameworks in ancient periods, since cultural communication, requirements, and encounters of today's societies are more expanded than the ancient periods, this concept has gotten a broader semantic scope and also, it has gotten more depth and expansion in terms of both theory and practice. So that, semantic expansion of this concept has become fitting to the people's needs and the today's societies' requirements. However, multicultural education, in its recent concept in the West, is a new issue and its history dates back to less than half a century. The start of this approach was in 1960 s and its golden age is considered in the mid 1980s. ${ }^{3}$

James Nebx, one of the pioneers of multicultural education, studies school as a social system in a multicultural platform. ${ }^{4}$ In his opinion, the concept of multicultural education is "equality of education". According to Banx, in order to preserve the environment of multicultural school, all the components of school should be studied and revised and changed in favor of multicultural education. The elements that should be revised include: policies, teachers' 
attitudes, educational materials, evaluation methods, consultation, and teaching methods. In the mid and late 1980s, other people including high school teachers, researchers such as Carl Grant, Christian Slitter, Jenuagi, and Sonia Nito provided more facilities for multicultural education and created new and deeper frameworks; frameworks that were based on the ideal of equal educational opportunities and the link between evolution of school and social transformation. For this purpose, in Banx's works, change does not refer to only quantitative change of curriculum. Rather, he criticizes the unfavorable situation which is an obstacle to elimination of this educational inequality, for example curiosity about people's situation and conditions, suppressive teaching approaches, and standardized tests. Multicultural curriculum movement has become caught in the stressful distance between the ideals and the reality. Many actions have been done in this regards around the worlds. Various associations have been created for promoting multicultural education. National council has been established for issuing the letter of credit of standards of educating the teacher training students regarding multiculturalism. Knowledge of the education authorities and teachers for teaching the students with different cultural backgrounds has been promoted. Sub-culture refers to a group which is smaller than the society. Subculture is related to a wider culture, because it accepts many of the norms and standards of the larger culture. But on the other hand, sub-culture is distinct from the culture of the whole society, because it has some specific norms and standards. ${ }^{5}$

Brake, English sociologist, considers subculture as a historic reaction to cultural modes and their formation originating from the efforts of each generation for solving structural problems, the efforts which are collectively experienced by the members of that generation. Generally, subcultures are groups which are paid attention as deviation from the principle standards of the society. They are formed based on age, gender, economic trends, race, etc. In terms of social analysis, subcultures are defined as having no right to political participation, being under governance, and ruled. People who scientifically study the subcultures consider them as opposed to other forms and the current culture. ${ }^{6}$ Sheikhavandi considers subcultures as the main element of identity of the nations and ethnicities and states that the identity of nations originates from their culture and subcultures. In other words, subcultures are called the sprouts and foliages of trunk of the society culture. Subcultures are considered as the main components of the culture of every society. Subcultures have a crucial role in education and curriculum planning systems, and without these subcultures, the society does not have full functions and true concepts. The term multiculturalism is a concept emphasized on in the recent years and refers to the fact that despite expanded communication between the countries and their movement towards a worldwide or at least regional system, the issue of nations and cultural differences between them has still a great importance. ${ }^{7}$

Multiculturalism tries to show that how sounds and experiences of different groups of people are silent and removed from the dominant cultural flow, and also it fights for challenging the different attitudes, experiences, and cultural forms by the groups who have become deprived of the dominant flow. Multiculturalism confirms the value of different types of cultures and cultural groups and asserts that for example black people, redskin people, Asians, and native Americans have their value and importance. ${ }^{9}$

The first conceptualization of the concept of multiculturalism dates backs to 1960s and this concept has had many changes. As other educational concepts, various definitions have been proposed for this concept and most of the experts try to explain this concept based on their perspectives. Some definitions focus on the students, some others focus on teachers' characteristics such as the teacher's culture, the ways of the teacher's dealing with classroom issues or teaching method, and some others focus on specific features of schools such as systematization and organizational framework, standard ranking or discrimination in allocating financial resources, some others focus on improving the schools in all aspects, and cultural characteristics of different groups, and some others consider multicultural education as a change of curriculum which is simply made by adding new and various materials in the curriculum. ${ }^{9}$

Multicultural education includes at least three elements:

a) An idea or concept

b) An educational reform movement

\section{c) A process}

This kind of education is based on commitment to pluralism and is aimed at directing the learners to become prepared for actively participate in a diverse and democratic society. In other words, in this approach, all the learners should benefit from equal educational opportunities regardless of the group to which they belong. Multicultural education is an effort for releasing the learners from ethnical constraints and making them aware of the confrontation of the cultures, societies, and others' thoughts and life styles. The ultimate goal of this education is enabling the learners to look at the work $1 \mathrm{ld}$ without any fanaticism and prejudice and to be able and willing to explore its variety and riches.

According to Gay, ${ }^{9}$ the importance of multicultural education is due to at least three elements:

a) Social realities

b) The effect of human's culture and race on his/her growth and progress

\section{c) Effective teaching and learning conditions}

Social reality: our world is a (socially) plural, and multilayer world with different nations and races. Racial, cultural, ethnic, and language diversities are considered as the most prominent features of today's world. Researches such as the work done by Smith suggested that when ethnic groups become grow wider and get political importance, social policies and programs should meet their needs too.

The effect of human's culture and race on his growth and progress: culture forms human's behaviors, attitudes, and values. In a pluralistic society, responsive educational decision making will be achieved when the education leaders plan their educational programs being aware of the way of formation of their own and their students' attitudes, values, and behaviors by culture. ${ }^{9}$

Effective teaching and learning conditions: in multicultural education, teaching and learning are considered as cultural processes. In order to achieve the best (qualitatively) education, the students' culture should be carefully reviewed and analyzed. In other words, most of the differences between the students' learning process are due to their cultures. About the relationship between culture, teaching, and learning, Sadeghi ${ }^{9}$ has stated that:

a) Multicultural education is a basis for all the students in a pluralistic society in terms of culture, ethnicity, and sociality.

b) Nationality and culture are effective variables forming the individual identity and behavior. 
c) Cultural sociability first deeply roots in human's personality and then remains for life.

d) Cultural diversity is today's reality of the international community.

e) Multicultural education is a complement for qualitative education.

f) Nationality, culture, and humanity are inseparably interconnected and have mutual relationship with each other.

In his study titled "multicultural education as an educational approach, investigating and reflecting on the concept of multicultural education, considers it as an effort for releasing the children from ethnical constraints and making them aware of the existence of cultures, societies, and data of others' thoughts and lives. In their study titled "the effect of globalization on national identity (case study: students of public universities of Tehran)", Hafeznia ${ }^{10}$ concluded that expanded globalization processes in the form of information and communication technology has led to strengthened transnational identity of students. In this research, Banx $x^{4}$ concluded that the future teachers are still getting prepared to teach in idealistic schools of white skinned, monolingual, and middle class children. Also, most of the teachers of social sciences are not familiar with the concepts and goals of multicultural education. In his study, Smith ${ }^{6}$ concluded that background experiences of the teachers are valuable for enlightening and raising the understanding ability of pre-service teachers about perspectives and viewpoints of multicultural teaching.

\section{Research method}

The present research is a cross-sectional explanatory research that has been done as a survey and using the tool of questionnaire. The research population includes all the teachers of girls' elementary schools in Bojnord city who are 100 people. In this research, total count sampling method had been used. So, all the 100 people of the population were selected. Data collection method is a researcher-made questionnaire. After that validity (professors' and experts' judgment) and reliability (obtained as $0 / 86$ by using Cronbach's alpha) of the questionnaire were approved, it was distributed among the elementary teachers. Descriptive and inferential statistical methods were used for analyzing the data. In descriptive statistics, central and dispersion indexes such as mean and standard deviation were used, and in inferential statistics, exploratory factor analysis and confirmatory factor analysis were used at the confidence level of $95 \%$ by using SPSS 18 and LISEREL 8/8 software.

\section{Research findings}

In the present research using LISEREL structural model software, effectiveness of each factor was measured and finally, they were ranked, the results of which are presented in the following. Regarding the output of LISEREL software and the obtained value of path coefficient, among the recognized factors influencing multiculturalism, the structural dimension with the factor loading of $0 / 51$ is in the second degree of importance after the content dimension with the factor loading of $0 / 85$. 1 . In the following, communication path of each of the recognized dimensions and components in multicultural education (related to obvious (tangible) variables and hidden (intangible) variables) and also standard and significance coefficients of the measuring equation are presented (Figures 1-4).

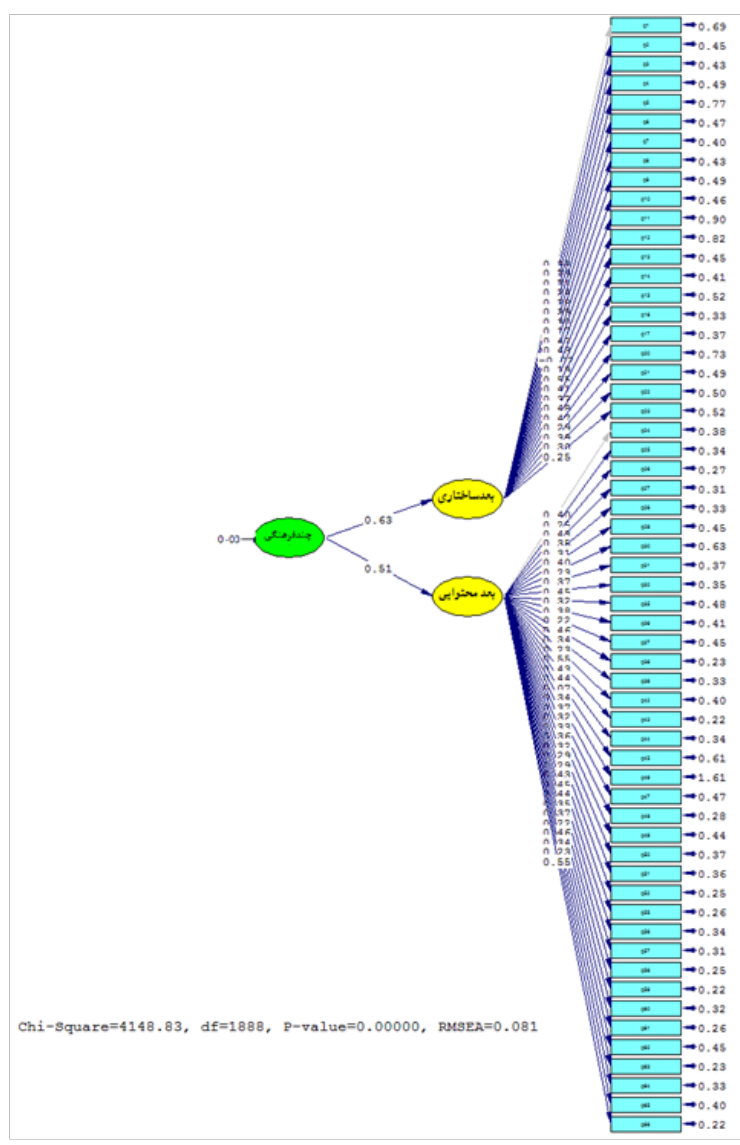

Figure I Structural model of the research in the standard mode.

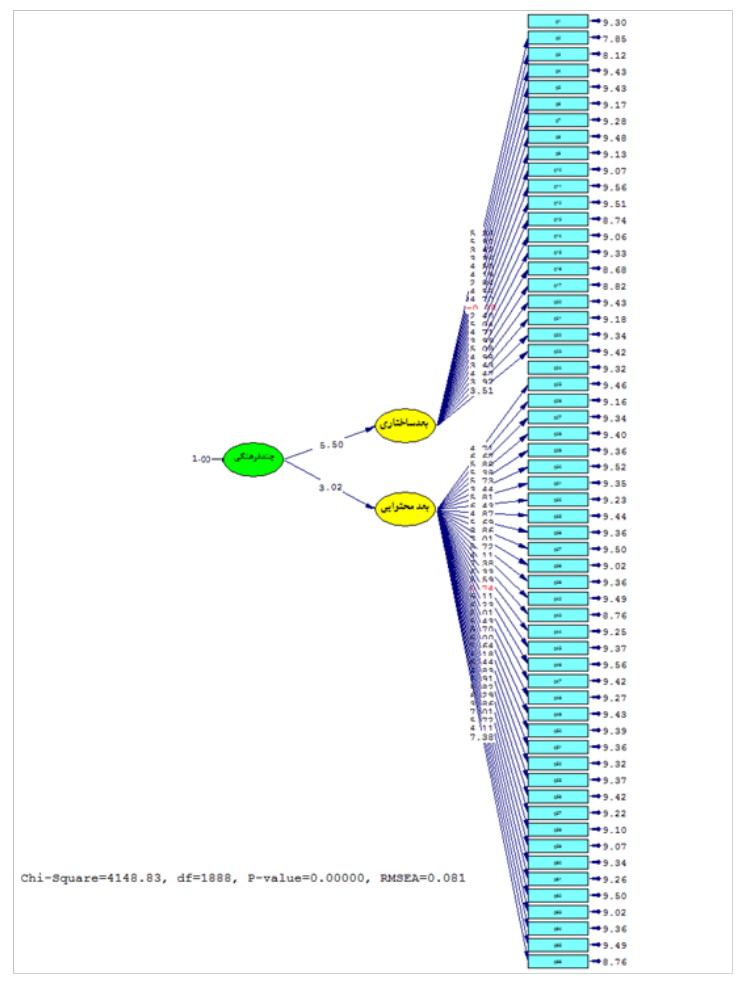

Figure 2 Structural model of the research in the significance mode. 


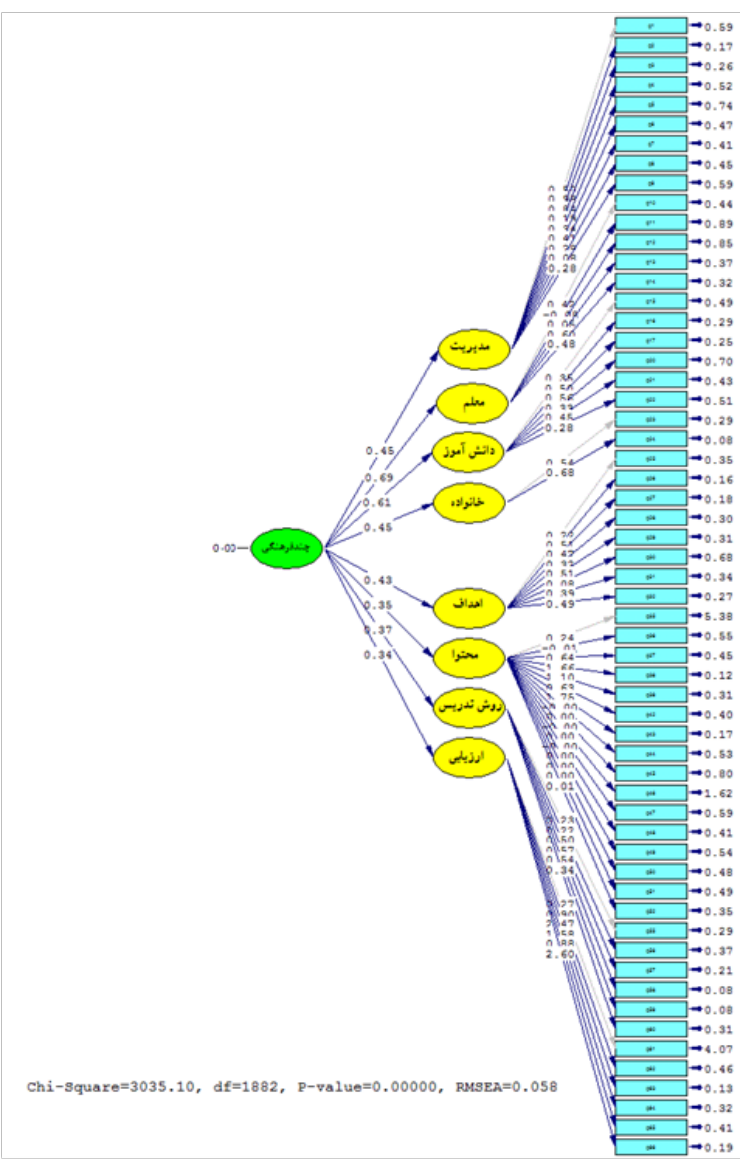

Figure 3 Structural model of the research in the standard mode.

Table 1 according to the output of LISEREL software and the values of path coefficient obtained in the above table, the component of the teacher with the path coefficient of 0/69 from the structural dimension and the component of the goals with the factor loading of
0/43 from the content dimension have the highest effect among the components recognized as being effective on multicultural education, and the other components are at the lower degrees.

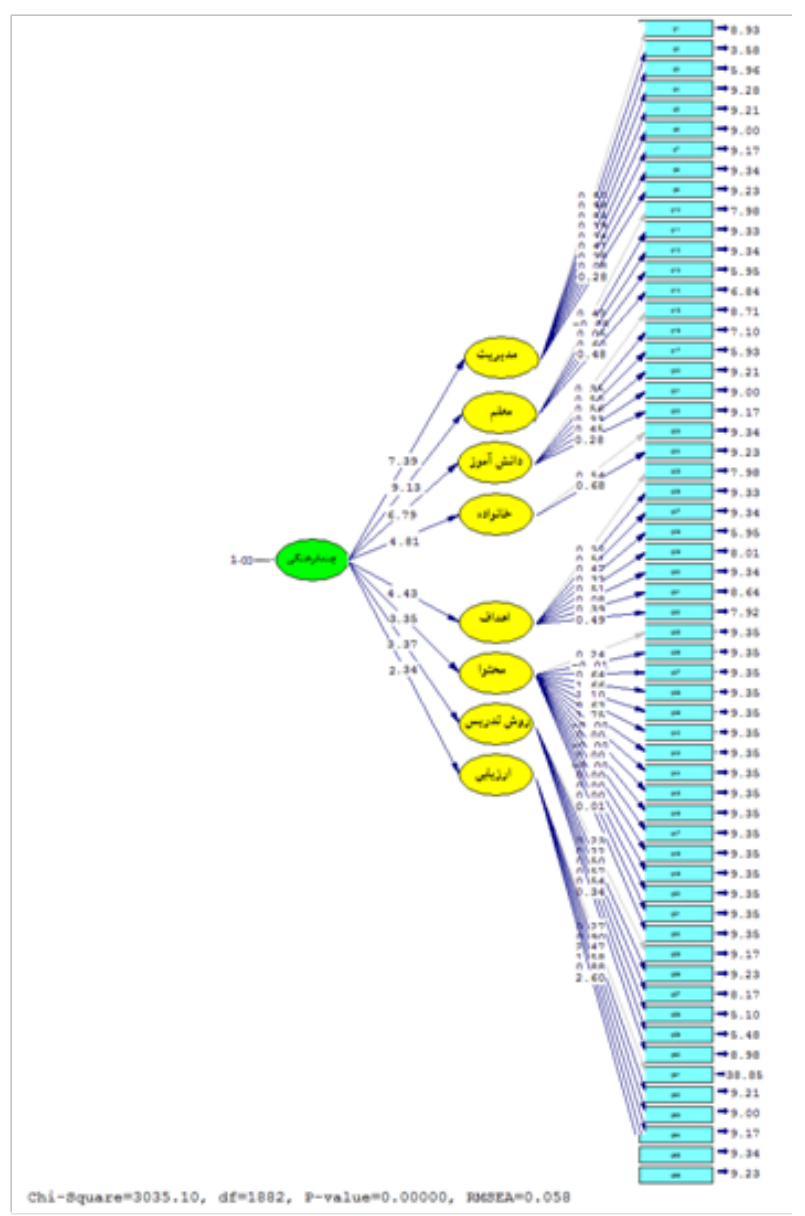

Figure 4 Structural model of the research in the significance mode.

Table I Direct coefficients of communication path of the most effective components

\begin{tabular}{llllll}
\hline No. & Component (communication path) & Path coefficient & Significance & Result & Rank \\
\hline I & Management & $0 / 45$ & Jul-39 & Is significant. & 3 \\
2 & Teacher & $0 / 69$ & Sep-13 & Is significant. & I \\
3 & Student & $0 / 6$ I & Jun-79 & Is significant. & 2 \\
4 & Family & $0 / 45$ & Apr-8| & Is significant. & 4 \\
5 & Goals & $0 / 43$ & Apr-43 & Is significant. & 5 \\
6 & Content & $0 / 35$ & Mar-35 & Is significant. & 7 \\
7 & Teaching method & $0 / 37$ & Mar-37 & Is significant. & 6 \\
8 & Evaluation & $0 / 34$ & Feb-43 & Is significant. & 8 \\
\hline
\end{tabular}

\section{Discussion and conclusion}

The world we live in includes a wide range of different races, nations, and cultures, and education of the student belonging to these diverse cultures is accompanied by many difficulties and complexities. Efficiency of education system in pluralistic societies culturally depends on multiple elements. One of these important elements is the teacher who must be familiar with the bases of multicultural education in order to be successful in teaching in a multicultural society. Therefore, in addition to accepting the issue of multiculturalism and the necessity of multicultural education in the state education system, teacher training centers should make effort for education of the knowledge, intuition, and skills required for achieving the goals of multicultural education in the schools. However, the real practice and the amount of emphasis on cultural education in administrative and educational mechanisms and the 
content of courses and curriculums should be contemplated. On the other hand, education is a time-consuming, fruitful, and also difficult process in which teachers are the starting point of any educational evolution. So that, in the age of facing with global challenges, making a change in the society will not be possible unless by thoughtful and creative teachers. The need to competent, knowledgeable, and powerful teachers is felt in every era, especially in the present day which is the age of research, technology, informatics, and explosion of knowledge and information. The emphasis on the teachers' central role is due to the fact that they are considered as the correspondents of education, and the active goals and purposes of education systems in different aspects should be realized by the teachers. ${ }^{11}$ In the mid 70 s, people around the world found that education department cannot and should not ignore this major element and so, they founded a new education system in which teachers are considered as the bases and foundations. The period of the $80 \mathrm{~s}$ can be named as the decade of warning thinkers and researchers about the necessity of changing and improving the quality of teacher training. In this decade, in every book about economic, social, cultural, and even political changes published by new thinkers, they seriously pointed to the issue of teacher and changing the teaching-learning methods and principles. Their statements suggested the fact as is every fundamental change is subject to making a change in education system and no changes are made in a system unless the necessary changes are made in education practices. ${ }^{12}$ In the late $90 \mathrm{~s}$, the basic characteristics of education in 21 th century were considered and the teachers' role was changes from a mere provider of knowledge and information to a director and facilitator of the teaching-learning process, and the most important characteristics of the teachers of this century were considered as creative thinking, leading the learners to knowledge production and guiding them in the teaching-learning process. In other words, being a thoughtful teacher was considered as the important characteristics of the teachers in 21 th century. Some of the characteristics of a thoughtful teacher have been recounted as flexibility, collaboration with others, innovation, being a questioner, and creativity. ${ }^{13}$ The importance of teacher training and the suggestions and emphases in this field have made it necessary to paying attention to reforming the teacher training systems and adopting logical measures for improving the professional teacher training. One of the most important theories that have been raised in this field in recent decades is Donald Schon's ${ }^{14}$ theory of thoughtful acting and thoughtful teaching which has gained a lot of attention in the field of education and a large mass of educational research has been done on it. This theory has also attracted a great deal of attention as a pattern for teacher training. Gimenez ${ }^{15}$ has named the period of the $90 \mathrm{~s}$ as the decade of reflection on teacher training. He states that although the meaning of reflection is not exactly obvious, nowadays anyone who discusses the issue of teacher training cannot ignore this concept. Donald Schon has criticized the positivistic approach which dominates the professional education and teacher training system of America that is called technical rationality. He states that such education is based on two basic presuppositions:

a) Academic research provides useful professional knowledge. ${ }^{15}$

b) This professional knowledge, in the case of being taught in teacher training centers, makes the students prepared for the needs of the real world.

Following Dewey and Schon, many approaches were created in teacher training whose goal was to train thoughtful teachers who are willing to make intelligent decisions about what to teach. Nevertheless, these approaches have not had any agreement about the fact that what exactly is reflection. Depending on the knowledge bases on which each of these approaches are based or the purposes which they have considered for reflection and the role or responsibility that they consider for the teacher, and generally the ideologies dominating their curriculum, different approaches have been mentioned that cover a wide range of conceptual differences and have consequently proposed different implications for organizing and designing teacher training courses. ${ }^{16}$

\section{Acknowledgments}

None.

\section{Conflicts of interest}

The author declares that there are no conflicts of interest.

\section{References}

1. Sajadi Reza. Action research: a strategy for improving education and teaching. Journal Higher Education Research \& Development. 2006;13(1):45-58

2. Miller M. Recommendations for teacher educators and professional developers. In: Mohr M, Rogers C, Stanford B, editors. Teacher research for better schools. New York: Teachers College Press; 2003. Pp. 96-106.

3. Resnik LS. Cooperative schools for student teachers. Progressive education. 2009;8:5-251.

4. Banx Juan Manuel. Do the initial and the continuous teachers' professional development sufficiently prepare teachers to understand and cope with the complexities of today and tomorrow's education? Journal of Eductional Change. 1986;8(2):169-173.

5. Tavasoli Hashem. Educational designing from the perspective of behaviorism, cognitivism, and constructivism approaches. Humanities scientific-research quarterly journal of Al-Zahra University. Seventh and eighth year. 2002. pp. 102-120.

6. Smith R. Reflections on reflection: a critical appraisal of reflective practice in L1 teacher education. System 35. 2003;35(2):192-207.

7. Khosravi Yahya, Marzoughi Rahmatollah. Comparative study of the aspects of meta-cognitive awareness of middle school students. Universal Journal of Educational Research. 2008;4(1):165-172.

8. Kalhor Lotfali. Investigation and analysis of general teaching abilities in curriculum of two-year teacher training course in Iran. Language Testing in Asia. 2010;8(9):25-82.

9. Sadeghi Aliakbar. Epistemological bases of constructivism, and teaching-learning implications. Tehran: Tarbiat Modares University, faculty of humanities; 2011. 3 p.

10. Hafeznia Mohammad Javad. The effect of globalization on national identity (case study: students of public universities of Tehran. research journal of Tehran University. 2014;14(2):131-156.

11. Mehrmohammadi Mahmoud. Reflection on teaching-learning process and teacher training, first edition. Tehran: Madreseh publication; 2015.

12. Raouf Ali. Teacher training and practice. 2nd ed. Tehran: Fatemi publications; 2013. $11 \mathrm{p}$.

13. Majdfar Morteza. Educating and training thoughtful teachers (a look at new perspectives to the teachers' role). Roshd journal for teachers. 2002;15(1):52-85.

14. Schön D. The Reflective Practitioner: How Professionals Think in Action. New York: Basic Books; 2011.22 p

15. Gimenez W. The quality school: Managing students without coercion. New York: Harper \& Row; 1999. 171 p.

16. Emam Jomeh, Seyyed Mohammadreza. A Comparative Study of Teacher Education in Iran and the UK. Tarbiat Modares University. 2006. 7 p. 